\title{
Discussion about clinical value of detection of IL-10, IL-1 $\beta$, IL-6, MCP-1, TNF- $\alpha$, IP-10 and IL-4 for the diagnosis of COVID-19
}

\author{
Qingqing $\mathrm{Lu}^{1}$, Zhenhua Zhu², Hui Zhou ${ }^{2}$, Yan $\mathrm{Hu}^{2}$, Ge Shen ${ }^{3}$, Pan Zhu ${ }^{3}$, Gang Yang ${ }^{3}$, and \\ Xiaobing $\mathrm{Xie}^{2}$ \\ ${ }^{1}$ Hunan University of Chinese Medicine \\ ${ }^{2}$ The First Hospital of Hunan University of Chinese Medicine \\ ${ }^{3}$ Loudi Center for Disease Control and Prevention
}

June 1, 2020

\begin{abstract}
Objective: Analyse the relationship between COVID-19 with IL-10, IL-1 $\beta$, IL-6, MCP-1, TNF- $\alpha$, IP-10 and IL-4. Methods: The serum levels of cytokines above were detected by ELISA. Results: Most of the serum level of cytokines above in patients with COVID-19 were significantly higher than those in healthy people, and some of them were significantly higher than those in patients with other diseases. AUC of COVID-19 diagnosed by they were $0.735,0.775,0.595,0.821,0.848,0.387$ and 0.987 . The serum levels of some cytokines in male patients had noticeably higher than those in female patients. The serum level of almost all cytokines of the elderly was higher than that of the youth and middle-aged patients. The serum level of IP-10 in patients with COVID-19 was positively correlated with IgM, while TNF- $\alpha$ was negatively correlated with IgG. The levels of cytokines in patients were higher at 25 days after onset than at 20 days, TNF- $\alpha$ and IL- 4 were significantly lower at 30 days than at 25 days, while IP-10 were reversed. Conclusion: The detection of cytokines have some clinical value for diagnosis of COVID-19, and that of IL-4 and TNF- $\alpha$ was the best. The levels of cytokines in patients have some relationships with gender, age and course of disease.
\end{abstract}

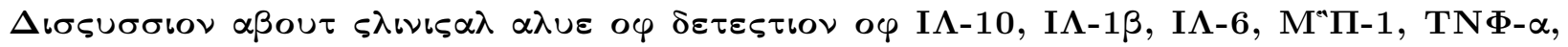

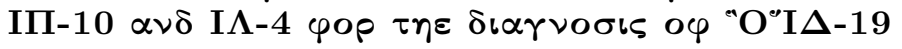

Qingqing $\mathrm{Lu}^{1}$,Zhenhua Zhu ${ }^{2}$,Hui Zhou ${ }^{2}$,Yan $\mathrm{Hu}^{2}$,Ge Shen ${ }^{3}$,Pan Zhu ${ }^{3}$,Gang Yang ${ }^{3}$,Xiaobing Xie ${ }^{2}$

(1. Hunan University of Chinese medicine, Changsha Hunan Postal Code: 410208; 2. The First Hospital of Hunan University of Chinese Medicine, Changsha Hunan Postal Code: 410007; 3. Loudi Center for Disease Control and Prevention,Loudi Hunan Postal Code: 417000)

* Fund project: Innovative provincial construction special novel coronavirus pneumonia emergency response special topic in Hunan province science and Technology Department 2020 (2020SK3009);Novel coronavirus molecular diagnosis technology and development and clinical application of mobile system(2020SK3018).

${ }^{C}$ orrespondenceauthor, E-mail : xxiaobing888@163.com

Abstract: Objective : Analyse the relationship between COVID-19 with IL-10, IL-1 $\beta$, IL-6, MCP-1, TNF$\alpha$, IP-10 and IL-4.Methods: The serum levels of cytokines above were detected by ELISA. Results: Most of the serum level of cytokines above in patients with COVID-19 were significantly higher than those in healthy people, and some of them were significantly higher than those in patients with other diseases. AUC of COVID-19 diagnosed by they were $0.735,0.775,0.595,0.821,0.848,0.387$ and 0.987 . The serum levels of some cytokines in male patients had noticeably higher than those in female patients. The serum level of almost all cytokines of the elderly was higher than that of the youth and middle-aged patients. The serum 
level of IP-10 in patients with COVID-19 was positively correlated with IgM, while TNF- $\alpha$ was negatively correlated with IgG. The levels of cytokines in patients were higher at 25 days after onset than at 20 days, TNF- $\alpha$ and IL- 4 were significantly lower at 30 days than at 25 days, while IP-10 were reversed. Conclusion: The detection of cytokines have some clinical value for diagnosis of COVID-19, and that of IL- 4 and TNF- $\alpha$ was the best. The levels of cytokines in patients have some relationships with gender, age and course of disease.

\section{Keywords: cytokine; COVID-19; clinical value;}

Coronavirus disease 19 (COVID-19) was first discovered in Wuhan, Hubei in December 2019, then the epidemic spread throughout China and other countries and regions abroad. The virus has high infectivity and caused serious damage to the global economy and the health of people all over the world. The main methods for diagnosing novel coronavirus (SARS-CoV-2) were nucleic acid detection and serological antibody detection. According to diagnosis and treatment plan of COVID-19 (trial version 7) issued by the office of the Chinese health and Health Commission and the office of the State Administration of traditional Chinese medicine, inflammatory factors were often increased in severe and critical patients ${ }^{[1]}$. The immune system has three functions including immune defense, immune surveillance and immune self stability, immune self stability was mainly maintained by two mechanisms: autoimmune tolerance and immune regulation; the immune response was structured in innate immunity and adaptive immunity, and the former one was the first line of defense against pathogen invasion. The immune cells can secrete cytokines (CKs) such as interleukin (IL), colony-stimulating factor (CSF), chemokine, interferon (IFN), tumor necrosis factor ( TNF) and growth factor (GF) which can induce the activation, proliferation or migration of target cells by binding to specific receptors on a variety of cells when the body was immune to exogenous substances ${ }^{[2]}$. Our study aims at detect the expression level of IL-10, IL-1 $\beta$, IL-6, monocyte chemoattractant protein-1 (MCP-1), TNF- $\alpha$, interferon-inducible protein -10 (IP-10) and IL-4 in the blood of in patients with COVID-19, patients with other diseases and healthy people, and discuss its diagnostic value for diagnosis of COVID-19.

\section{Materials and methods}

\subsection{Materials}

\subsubsection{Specimens}

The blood samples of patients (48 cases, 2 deaths) with COVID-19 were from Loudi City Disease Control Center, patients (53 cases, confirmed by positive nucleic acid test) with malignant tumor, blood system disease, rheumatic immune system disease and other diseases that increase the level of inflammatory factors, and healthy people (35 cases) were from The First Hospital of Hunan University of Chinese medicine. There were 69 males and 67 females, ranging in age from 7 to 96 years old. There was no significant difference in sex and age among the selected cases $(\mathrm{P}>0.05)$. There are 12 patients with COVID-19 who were tested once, 16 tested two times, 12 tested three times, 6 tested four times, 2 tested five times and 1 tested six times. All the selected cases and their families had informed consent.

\section{Instruments and reagents}

IL-10, IL-1 $\beta$, IL-6, MCP-1, TNF- $\alpha$, IP-10 and IL-4 test kits were purchased from human diagnostic products (Beijing) Co., Ltd. and TECAN 200-8 were purchased from TECAN (Shanghai) trading company. SASCoV-2 antibody test kit (colloidal gold immunochromtographic assay, Guangzhou Wanfu Biotechnology Co., Ltd.) and SAS-CoV-2 IgM and IgG antibody test kit (chemiluminescent immunoassay, purchased from Shenzhen yahuilong Biotechnology Co., Ltd.) were selected for serum antibody test.

\subsection{Method}

The serum samples of all cases were vein blood of 12 hours fasting, and have centrifugated at 4000R / min for 10min. ELISA was used in this experiment. Operate accordance with the kit instructions in strict.

\subsection{Statistical analyse}


All datas were processed by IBM SPSS statistic 21. According to the characteristics of data distribution, T-test was utilized to test the two independent samples of counting data. The difference was statistically significant $(\mathrm{P}<0.05)$.

\section{Results}

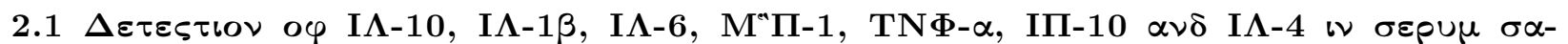

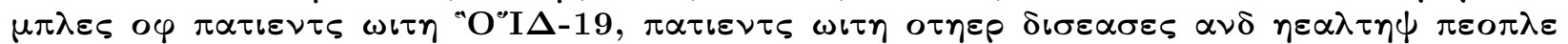
$\beta \psi \mathrm{E} \Lambda \mathrm{I} \Sigma \mathrm{A}$

After statistical analyse, as Table 1 shows, it was found that the level of IL-10, IL-1 $\beta$, MCP-1, TNF- $\alpha$, IP-10 and IL-4 in the serum of patients with COVID-19 was significantly higher than that in the serum of healthy people $(\mathrm{P}=0.006,0.000,0.001,0.000,0.024,0.000)$. The level of IL-6 in the serum of patients with COVID-19 was higher than that in the serum of healthy people, but there was no significant difference (P $=0.054)$. The serum levels of IL-10, MCP-1 and IL-4 in patients with COVID-19 were significantly higher than those in patients with other diseases $(\mathrm{P}=0.003,0.001,0.000)$, the serum levels of IL-6 in patients with COVID-19 were significantly lower than those in patients with other diseases $(\mathrm{P}=0.000)$, while the serum levels of IL-1 $\beta$, TNF- $\alpha$ and IP-10 in patients with COVID-19 and healthy people were not significantly different $(\mathrm{P}=0.158,0.159,0.612)$.

Table 1 Levels of IL-10, IL-1 $\beta$, IL-6, MCP-1, TNF- $\alpha$, IP-10 and IL-4 in serum samples of patients with COVID-19, patients with other diseases and healthy people by ELISA

$? \mathrm{x} \pm \mathrm{SD}(\mathrm{pg} / \mathrm{ml})$

\begin{tabular}{|c|c|c|c|c|c|c|c|c|}
\hline group & $\mathrm{n}$ & IL-10 & IL-1 $\beta$ & IL-6 & MCP-1 & TNF- $\alpha$ & IP-10 & IL-4 \\
\hline $\begin{array}{l}\text { patients } \\
\text { with } \\
\text { COVID-19 }\end{array}$ & 120 & $\begin{array}{l}7.53 \pm 1.35 \\
* \#\end{array}$ & $6.32 \pm 0.48 *$ & $\begin{array}{l}10.72 \pm 2.65 \\
\#\end{array}$ & $\begin{array}{l}105.44 \pm 16.18 \\
* \#\end{array}$ & $\begin{array}{l}19.98 \pm 3.40 \\
*\end{array}$ & $\begin{array}{l}74.15 \pm 16.63 \\
*\end{array}$ & $\begin{array}{l}43.81 \pm \\
* \#\end{array}$ \\
\hline $\begin{array}{l}\text { Healthy } \\
\text { people }\end{array}$ & 35 & $0.84 \pm 0.12$ & $0.26 \pm 0.12$ & $0.10 \pm 0.05$ & $13.30 \pm 2.88$ & $1.18 \pm 1.16$ & $42.45 \pm 7.06$ & $0.05 \pm 0$ \\
\hline $\begin{array}{l}\text { patients } \\
\text { with } \\
\text { other } \\
\text { deseases } \\
\mathrm{P}\end{array}$ & 53 & $2.03 \pm 0.27$ & $2.19 \pm 0.92$ & $25.68 \pm 5.57$ & $28.66 \pm 5.64$ & $6.68 \pm 2.94$ & $85.53 \pm 16.15$ & $0.15 \pm 0$ \\
\hline
\end{tabular}

Tip:*means $\mathrm{P}<0.05$ when compare with healthy people, and \# means $\mathrm{P}<0.05$ when compare with patients with other diseases.

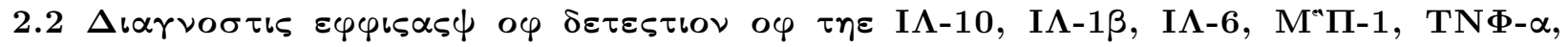 III-10 $\alpha \nu \delta$ I $\Lambda-4$ ov "O"I $\Delta-19 \beta \psi$ E $\Lambda \mathrm{I} \Sigma A$}

The ability of prediction of IL-10, IL-1 $\beta$, IL-6, MCP-1, TNF- $\alpha$, IP-10 and IL-4 on COVID-19 was assessed by ROC curve. As figure 1 shows, AUC of COVID-19 diagnose by they were $0.735,0.775,0.595,0.821,0.848$, 0.387 and 0.987 , respectively. The sensitivity of diagnosis of IL- 4 , TNF- $\alpha$, MCP-1, IL-1 $\beta$, IL-10 and IL-6 were $99.1 \%, 81.2 \%, 84.6 \%, 63.2 \%, 65.8 \%$ and $72.6 \%$, and the specificity of they were $98.8 \%, 93.0 \%, 69.8 \%$, $95.3 \%, 89.5 \%$ and $64.0 \%$; the sensitivity and specificity of combined diagnosis of IL- 4 and TNF- $\alpha$ were $99.8 \%$ and $99.9 \%$, respectively. 


\section{ROC curve}

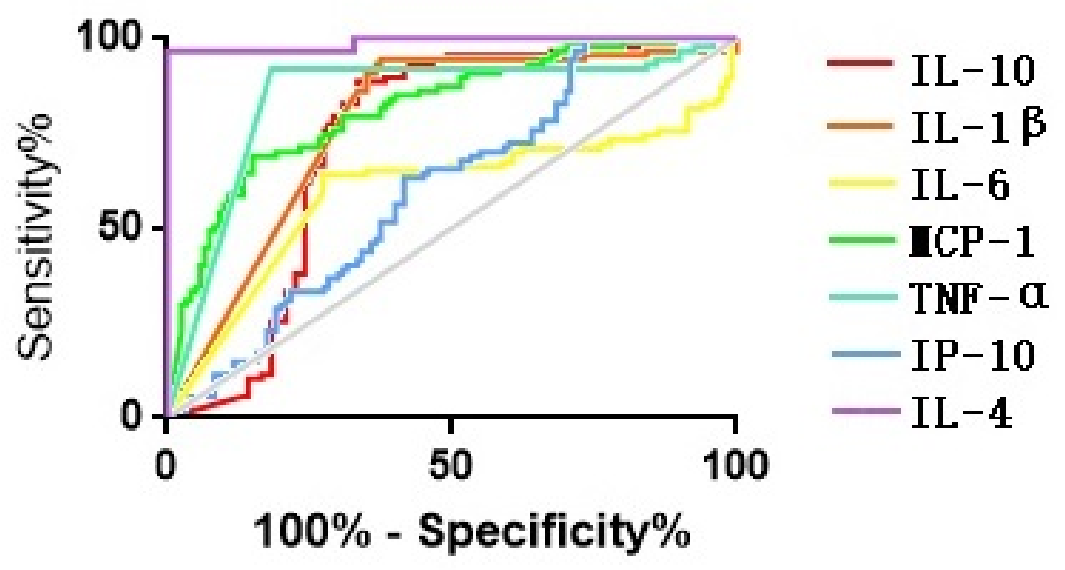

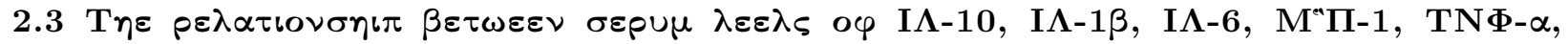

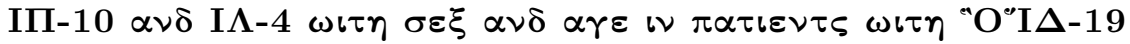

According to the statistical analyse, as Table 2 shows, it was found that the serum levels of IL-10, MCP1, TNF- $\alpha$ and IL-4 in male patients with COVID-19 were remarkably higher than those in female patients $(\mathrm{P}=0.017,0.004,0.035,0.012)$, while the serum levels of IL-1 $\beta$, IL-6 and IP-10 in male patients with COVID19 were not remarkably different from those in female patients $(\mathrm{P}=0.057,0.278,0.085)$.

Table 2 Serum levels of IL-10, IL-1 $\beta$, IL-6, MCP-1, TNF- $\alpha$, IP-10 and IL-4 in patients with COVID-19 in different genders

$? \mathrm{x} \pm \mathrm{SD}(\mathrm{pg} / \mathrm{ml})$

\begin{tabular}{llllllll}
\hline Group & $\mathrm{n}$ & $? \mathrm{x} \pm \mathrm{SD}(\mathrm{pg} / \mathrm{ml})$ & $? \mathrm{x} \pm \mathrm{SD}(\mathrm{pg} / \mathrm{ml})$ & $? \mathrm{x} \pm \mathrm{SD}(\mathrm{pg} / \mathrm{ml})$ & $? \mathrm{x} \pm \mathrm{SD}(\mathrm{pg} / \mathrm{ml})$ & $? \mathrm{x} \pm \mathrm{SD}(\mathrm{pg} / \mathrm{ml})$ & $? \mathrm{x} \pm \mathrm{SD}(\mathrm{pg} / \mathrm{ml})$ \\
\hline & & $\mathrm{IL}-10$ & $\mathrm{IL}-1 \beta$ & IL-6 & MCP-1 & TNF- $\alpha$ & IP-10 \\
male & 75 & $9.39 \pm 2.11$ & $6.30 \pm 0.61$ & $12.95 \pm 4.25$ & $129.02 \pm 24.63$ & $22.70 \pm 3.60$ & $92.23 \pm 24.46$ \\
female & 37 & $5.29 \pm 0.65$ & $7.73 \pm 0.81$ & $8.69 \pm 1.19$ & $69.62 \pm 13.74$ & $18.50 \pm 2.25$ & $53.42 \pm 20.29$ \\
$\mathrm{P}$ & $/$ & 0.017 & 0.057 & 0.278 & 0.004 & 0.035 & 0.085 \\
\hline
\end{tabular}

Depending on the collected cases, patients with COVID-19 were divided into adolescents (aged from 0 to 35 years old), middle-aged people (aged from 36 to 59 years old) and elderly people (60 years old and above). According to the statistical analyse, as Table 3 shows, the level of MCP-1 in the serum of the elderly was remarkably higher than that of adolescents and middle-aged patients $(\mathrm{P}=0.015,0.000)$, and the level of TNF$\alpha$ and IL-4 in the serum of the elderly was remarkably higher than that of middle-aged patients $(\mathrm{P}=0.002$, 0.035), but there was no significant difference in the levels of IL-10, IL-1 $\beta$, IL-6 and IP-10 between patients with COVID-19 at different ages ( $\mathrm{P}>0.05)$.

Table 3 Serum levels of IL-10, IL-1 $\beta$, IL-6, MCP-1, TNF- $\alpha$, IP-10 and IL-4 in patients with COVID-19 in different ages

$? \mathrm{x} \pm \mathrm{SD}(\mathrm{pg} / \mathrm{ml})$ 


\begin{tabular}{llllllll}
\hline Group & $\mathrm{n}$ & $? \mathrm{x} \pm \mathrm{SD}(\mathrm{pg} / \mathrm{ml})$ & $? \mathrm{x} \pm \mathrm{SD}(\mathrm{pg} / \mathrm{ml})$ & $? \mathrm{x} \pm \mathrm{SD}(\mathrm{pg} / \mathrm{ml})$ & $? \mathrm{x} \pm \mathrm{SD}(\mathrm{pg} / \mathrm{ml})$ & $? \mathrm{x} \pm \mathrm{SD}(\mathrm{pg} / \mathrm{ml})$ & $? \mathrm{x} \pm \mathrm{SD}(\mathrm{pg}$ \\
\hline & & $\mathrm{IL}-10$ & IL- $\beta$ & IL-6 & MCP-1 & TNF- $\alpha$ & IP-10 \\
Young & 46 & $6.20 \pm 2.55$ & $6.10 \pm 0.78$ & $5.93 \pm 0.78$ & $71.82 \pm 28.74 \#$ & $19.73 \pm 6.61$ & $52.69 \pm 27.2$ \\
Middle-aged & 32 & $6.71 \pm 1.28$ & $6.55 \pm 0.87$ & $10.87 \pm 1.85$ & $85.11 \pm 17.18 \#$ & $18.38 \pm 3.62 \#$ & $79.44 \pm 31.4$ \\
Elderly & 42 & $9.62 \pm 2.50$ & $6.38 \pm 0.88$ & $15.87 \pm 7.37$ & $157.75 \pm 30.04$ & $26.05 \pm 5.31$ & $93.61 \pm 28.4$ \\
P value & $/$ & $\mathrm{P}>0.05$ & $\mathrm{P}>0.05$ & $\mathrm{P}>0.05$ & $\mathrm{P}>0.05$ & $\mathrm{P}>0.05$ & $\mathrm{P}>0.05$ \\
\hline
\end{tabular}

Tip: *means $\mathrm{P}<0.05$ when compared with the middle-aged patients, and \#means $\mathrm{P}<0.05$ when compared with elderly patients

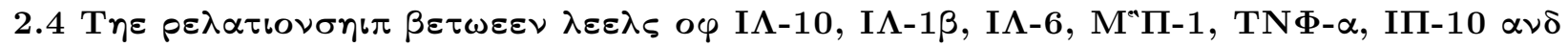

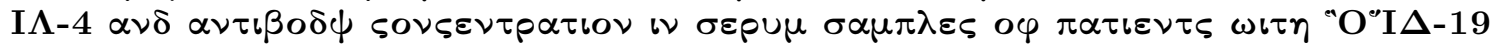

The correlation analyse of levels of IL-10, IL-1 $\beta$, IL-6, MCP-1, TNF- $\alpha$, IP-10 and antibody concentration in serum samples of patients with COVID-19 was shown in Table 4. It was found that the level of IP-10 in patients with COVID-19 was positively correlated with the level of IgM $(\mathrm{r}=0.255, \mathrm{P}<0.05)$, while the level of TNF- $\alpha$ was negatively correlated with the level of $\operatorname{IgG}(\mathrm{r}=-0.217, \mathrm{P}<0.05)$, but there was no significant correlation between the levels of IL-10, IL-1 $\beta$, IL-6, MCP-1 and IL-4 and the concentrations of IgG and IgM.

Table 4 Correlation Analyse of serum levels of IL-10, IL-1 $\beta$, IL-6, MCP-1, TNF- $\alpha$, IP-10 and antibody in patients with COVID-19

\begin{tabular}{lllllllll}
\hline Antibody & $\mathrm{n}$ & $\mathrm{r}$ & $\mathrm{r}$ & $\mathrm{r}$ & $\mathrm{r}$ & $\mathrm{r}$ & $\mathrm{r}$ & $\mathrm{r}$ \\
\hline & & $\mathrm{IL}-10$ & IL-1 & IL-6 & MCP-1 & TNF- $\alpha$ & IP-10 & IL-4 \\
IgM & 120 & 0.078 & -0.087 & 0.115 & 0.133 & 0.010 & $0.255^{*}$ & -0.104 \\
IgG & 120 & -0.150 & -0.179 & -0.103 & -0.160 & $-0.217^{*}$ & -0.097 & -0.176 \\
$\mathrm{P}$ & $\mathrm{P}>0.05$ & $\mathrm{P}>0.05$ & $\mathrm{P}>0.05$ & $\mathrm{P}>0.05$ & $\mathrm{P}>0.05$ & $\mathrm{P}>0.05$ & $\mathrm{P}>0.05$ \\
\hline
\end{tabular}

Tip: *means $\mathrm{P}<0.05$ 。

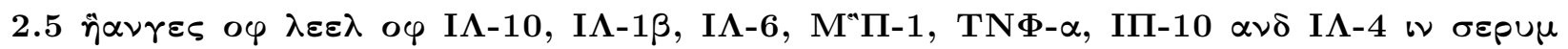

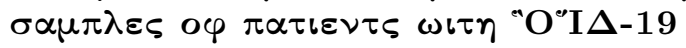

According to the statistical analysis, it takes 13-42 days (26.3 days on average) from the onset to discharge. The collected convalescent samples of COVID-19 were divided into groups according to the interval between collection time and onset time. The tests carried out 20 days after onset were counted as the first serological test (4 cases), the tests carried out 25 days after onset were counted as the second serological test ( 5 cases), and the tests carried out 30 days after onset were counted as the third serological test (10 cases), as shown in Figure 2. There was no significant difference in the serum levels of IL-10, IL-1 $\beta$, IL-6 and MCP-1. The level of TNF- $\alpha$ in the second test was higher than that in the first test, but there was no significant difference, while the level in the third test was significantly lower than that in the second test $(\mathrm{P}=0.014)$. The level of IP-10 in the second test was not significantly higher than that in the first test $(\mathrm{P}>0.05)$, but the level in the third test was significantly higher than that in the first and second test $(\mathrm{P}=0.035,0.031)$. The level of IL-4 in the second test was not significantly higher than that in the first test $(\mathrm{P}>0.05)$, but the level in the third test was significantly lower than that in the second test $(\mathrm{P}=0.019)$. 

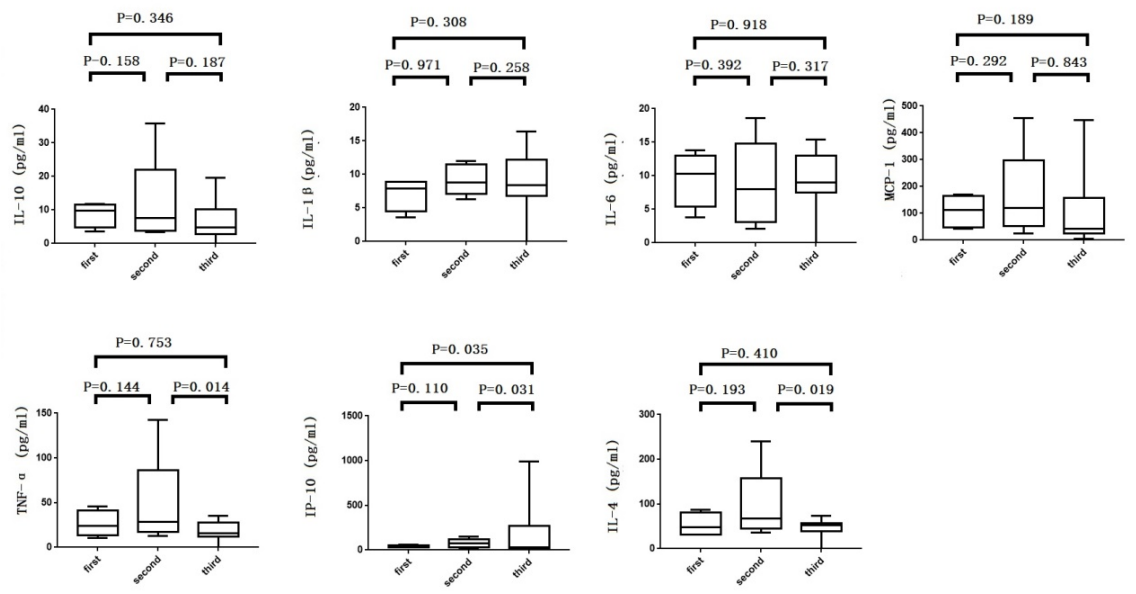

Figure 2 Comparison of serum level of IL-10, IL-1 $\beta$, IL-6, MCP-1, TNF- $\alpha$, IP-10 and IL-4 in patients with COVID-19

\section{Discuss}

A large number of proinflammatory cytokines may lead to abnormal immune response when the immune system is unbalanced, and it may leading to systemic inflammatory response syndrome (CRS), also known as cytokine storm, CRS can cause headache and fever, and it can cause disseminated intravascular coagulation and multiple organ system failure in severe cases $^{[3]}$. The level of cytokines has also changed a lot in patients with COVID-19, severe patients may have acute respiratory distress syndrome(ARDS), septic shock, metabolic acidosis that is difficult to correct, coagulation dysfunction or even multiple organ failure ${ }^{[1]}$, which may be related to CRS. CRS can be caused by graft-versus-host disease(GVHD), ARDS, sepsis, SARS, influenza, and so on, however, the types and levels of cytokines produced under different stimulation are different. The detection of the types and levels of cytokines can help to diagnose the disease. In addition, the production of cytokines is related to the individual immune function and level, so the severity of the disease can be predicted according to its level.IL-10 was produced by helper T cells (Th), killer T cells (Tk), B lymphocyte cells ( B cells), monocyte (MONO) and macrophage $(\mathrm{M} \varphi)$, and can inhibit the secretion of proinflammatory CKs such as IL-2, IFN $\gamma$, down-regulate MHC II of MONO, M $\varphi$ and DCs, and inhibit the proliferation and differentiation of Th1, these make it has the ability to antagonize inflammatory mediators, control the inflammatory response and avoid excessive tissue damage, but it can promote the differentiation of B cells. IL-1 $\beta$ was produced by MONO, M $\varphi$, DCs, natural killer cells (NK), B cells and endothelial cells, and can stimulate the activation of T-lymphocyte cells ( $\mathrm{T}$ cells), enhance the proliferation and maturation of B cells and the toxicity of NK cells by enhancing the expression of other proinflammatory CKs.It will be increases when Acute rejection of transplantation (ART) and it was an endogenous heat source. IL-6 was produced by $\mathrm{Th} 2$, MONO , M $\varphi$, DCs and bone marrow stromal cells, and can promote the proliferation of $\mathrm{T}$ cells which was important for the targeted differentiation of Th1 and follicular helper T cells (Tfh), promote the proliferation and differentiation of B cells and produce antibodies, and can promote the production of IgE by cooperating with IL-4, it can also induce acute phase protein expression, its receptor was the thrombopoietin receptor family, and it was an endogenous pyrogen. MCP-1 was produced by MONO, M $\varphi$, B cells and so on, and can chemotaxis and activate $\mathrm{MC}, \mathrm{M} \varphi$, T cells, basophils and DCs, it plays an important role in the occurrence and development of rheumatoid arthritis, glomerulonephritis, atherosclerosis, acute coronary syndrome, deep vein thrombosis and other diseases. Its receptor was the chemokine receptor family. TNF- $\alpha$ was produced by Th, MONO, M $\varphi$, DCs, mast cells, NK and B cells, and can regulate immune response, kill target cells, induce cells apoptosis, promote DCs maturation, and has tumor cytotoxic effect, it can lead to tissue damage, disseminated intravascular coagulation and even septic shock, while it has antiviral effect, it will increase when autoimmune diseases (AID) and ART, its receptor was the tumor necrosis factor receptor 
superfamily, and it was an endogenous heat source. IP-10 was produced by $\mathrm{T}$ cells induced by interferon, and can chemotactic MONO, activated T cells and NK cells, promote the cytolysis mediated by NK cells, and participate in the regulation of tumor angiogenesis. Its receptor was the chemokine receptor family. IL-4 was produced by Th2, Tk2, NK, mast cells, and so on, and can induce Th0 to transform into Th2 cells, activate and promote $\mathrm{B}$ cells proliferation and differentiation, stimulate $\mathrm{T}$ cells and mast cells proliferation, promote IgG1 and IgE synthesis, restrict anti-inflammatory mediators, control inflammatory reaction, avoid tissue over injury, and its receptor was thrombopoietin receptor family.

In order to determine the application value of the above-mentioned cytokine detection in the patients with COVID-19, the author detect the level of these cytokine in 120 serum samples of patients with COVID-19, 53 serum samples of patients with other diseases causing the rise of inflammatory factors and 35 serum samples of healthy people by ELISA, then the clinical characteristics and the expression of cytokines of patients with COVID-19 were analyzed combined with the detection results and relevant case data.The results showed that the level of IL-6 in the serum of patients with COVID-19 was higher than that in the serum of healthy people, but there was no significant difference. The level of IL-10, IL-1 $\beta$, MCP-1, TNF- $\alpha$, IP-10 and IL-4 in the serum of patients with COVID-19 was significantly higher than that in the serum of healthy people The level of MCP-1 and IL-4 in the serum of patients with COVID-19 was significantly higher than that of patients with disease control, and the level of IL- 6 in the serum of patients with COVID-19 was significantly lower than that of patients with other diseases. There are three highly pathogenic coronavirus diseases have been found, in the serum samples of patients with severe acute respiratory syndrome (SARS) and Middle East Respiratory Syndrome (MERS), levels of monocyte macrophages, neutrophils and serum proinflammatory cytokines such as IL-1, IL-6, IL-8, IP-10 and MCP-1 always raise ${ }^{[4]}$, while the level of IL-10 may reduce ${ }^{[5]}$, but level of IL-10 in the serum samples of patients with COVID-19 were raise. It should be noted that the serum levels of IL-10, MCP-1, TNF- $\alpha$ and IL-4 in the male patients with COVID-19 were significantly higher than those in the female patients; the serum levels of MCP-1 in the elderly were significantly higher than those in the youth and middle-aged patients; the serum levels of TNF- $\alpha$ and IL-4 in the elderly were significantly higher than those in the middle-aged patients; the serum levels of IP-10 and IgM in the COVID-19 patients The level of TNF- $\alpha$ was positively correlated with that of IgG.

To sum up, this study revealed that IL-10, IL-1 $\beta$, IL-6, MCP-1, TNF- $\alpha$ and IL-4 are important indexes for the detection of COVID-19, and the combined diagnosis of IL- 4 and TNF- $\alpha$ was the best, the sensitivity and specificity of their combined diagnosis can reach $99.8 \%$ and $99.9 \%$ respectively. The serum levels of IL-10, MCP-1, TNF- $\alpha$ and IL-4 in male patients with COVID-19 were significantly higher than those in female patients, which may be related to the attack of sars-cov-2 on male reproductive system. The continuous monitoring of the cured patients with COVID-19 showed that IL-10, IL-1 $\beta$, MCP-1, TNF- $\alpha$, IP-10 and IL4 were higher at 25 days than at 20 days, but not significantly higher. The level of TNF- $\alpha$ and IL-4 in the serum of 30 days after the onset of the disease decreased significantly, while the level of IP-10 in the serum of 30 days after the onset of the disease increased significantly, which may be because the immune system in the late stage of inflammation secreted more IP-10 to induce excessive apoptosis of immune cells in order to avoid losing its normal tissues, and the level of TNF- $\alpha$ and IL-4 also decreased. Due to the limited number of samples and enrollment, only 2 cases in this paper are dead patients, and there is no comparison of the levels of cytokines between light and severe patients, and only the cytokines in patients' serum are detected, and there is no discussion about the level of cytokines in patients' plasma and other body fluids. It has been reported that CRS often erupts in severe patients with COVID-19, and there are high levels of proinflammatory cytokines such as IL-1 $\beta$, IL-6, IL-7, IL-10, g-scf, IP-10, MCP-1, MIP-1a, TNF- $\alpha$ and IFN- $\gamma$ in serum ${ }^{[6-8]}$, Whether the cytokine level of patients in the early stage of disease (before severe disease) can predict the severity of the course of disease development of patients with new crown, it also needs more patients in the group and samples collected at a specific time for discussion and demonstration. The follow-up research will continue to increase the sample size to make the results more convincing.

\section{REFERENCES}

[1] The national health and Health Committee and the office of the State, Administra- 
tion of traditional Chinese medicine (TCM).Diagnosis and Treatment Protocol for COVID-19 (Trial version 7)(state health office Medical Letter No.184 (2020).[EB/OL].(2020-03-04)[2020-03-05] http://www.nhc.gov.cn/yzygj/s7653p/202003/46c9294a7dfe4cef80dc7f5912eb1989.shtml.

[2]Chousterman Benjamin G,Swirski Filip K,Weber Georg F. Cytokine storm and sepsis disease pathogenesis.[J]. Seminars in immunopathology,2017,39(5):517-528.

[3]Shimabukuro-Vornhagen Alexander,Gödel Philipp,Subklewe Marion,et al.Cytokine release syndrome.[J].Journal for immunotherapy of cancer,2018,6(1):56-56.

[4]Rudragouda Channappanavar,Anthony R. Fehr,Rahul Vijay,et al.Dysregulated Type I Interferon and Inflammatory MC nocyte-Macrophage Responses Cause Lethal Pneumonia in SARS-CoV-Infected Mice[J].Cell Host \& Microbe,2016,19(2):181-93.

[5]Channappanavar Rudragouda,Perlman Stanley.Pathogenic human coronavirus infections: causes and consequences of cytokine storm and immunopathology.[J].Seminars in immunopathology,2017,39(5):529-539.

[6]Chaolin Huang,Yeming Wang,Xingwang Li,et al.Clinical features of patients infected with 2019 novel coronavirus in Wuhan, China[J].The Lancet,2020,395(10223):497-506.

[7] Guo Lingxi,Wei Dong,Zhang Xinxin,et al.Clinical Features Predicting MC rtality Risk in Patients With Viral Pneumonia: The MuLBSTA Score.[J]. Frontiers in microbiology,2019,10:2752.

[8] Kim E S, Choe P G, Park W B, et al. Clinical Progression and Cytokine Profiles of Middle East Respiratory Syndrome Coronavirus Infection[J].Journal of Korean Medical Science,2016,31(11):1717-1725. 